\title{
A model for longitudinal mentoring and telementoring of laparoscopic colon surgery
}

\author{
Christopher M. Schlachta $\cdot$ A. Kent Sorsdahl · \\ Kevin L. Lefebvre · Marcie L. McCune • \\ Shiva Jayaraman
}

Published online: 3 April 2009

(C) Springer Science+Business Media, LLC 2009

\section{Erratum to: Surg Endosc}

DOI 10.1007/s00464-008-0221-5

The correct spelling of the second author's name is A. Kent Sorsdahl.

The online version of the original article can be found under doi:10.1007/s00464-008-0221-5.

C. M. Schlachta $\cdot$ S. Jayaraman

Canadian Surgical Technologies \& Advanced Robotics

(CSTAR), Lawson Health Research Institute, Schulich School

of Medicine and Dentistry, University of Western Ontario,

339 Windermere Road, London, ON, Canada N6A 5A5

\section{M. Schlachta $(\bowtie)$}

Departments of Surgery and Oncology, Schulich School of Medicine and Dentistry, University of Western Ontario, University Hospital, London Health Sciences Centre,

339 Windermere Road, London, ON, Canada N6A 5A5

e-mail: christopher.schlachta@lhsc.on.ca

A. K. Sorsdahl - K. L. Lefebvre · M. L. McCune Stratford General Hospital, 46 General Hospital Drive,

Stratford, ON, Canada N5A 2Y6 